\title{
LOS EXILIADOS ESPAÑOLES DE LA GUERRA CIVIL EN LOS CENTROS SUPERIORES DE ENSEÑANZA DE ECONOMÍA DEAMÉRICA LATINA
}

\author{
Manuel Martín Rodríguez ${ }^{1}$ \\ Universidad de Granada - España \\ mmartinr@ugr.es
}

Recepción: 24/02/2010

Evaluación: 15/07/2010

Aceptación: 12/11/2010

Artículo de Revisión

\section{RESUMEN}

Al final de la guerra civil española (1936-1939) muchos intelectuales se vieron obligados al exilio. Pese a que por esas fechas no existían en España estudios superiores de Economía, algunos de ellos terminaron dedicándose a la enseñanza de esta disciplina o trabajando en centros de investigación económica. En este artículo se estudian las aportaciones de este colectivo, muy poco conocido hasta ahora, a la enseñanza e investigación de la Economía en América Latina.

Palabras clave: Exilio, Guerra Civil española. Enseñanza Superior Economía.

\footnotetext{
Doctor en Ciencias Económicas. Correspondiente de la Real Academia de Ciencias Morales y Políticas (España). Académico de número de la Academia de Ciencias Sociales y del Medio Ambiente de Andalucía. Señor Associate Member del St. Anthony Collage de Oxford (UK). Catedrático de Economía Aplicada de la Universidad de Granada (España). Premio Andalucía de Economía y Hacienda Autonómica. Es autor de numerosas publicaciones científicas, buena parte de ellas en el campo de la institucionalización de los estudios de Economía en la Universidad española, en el que es un reconocido especialista. Su más reciente libro es Análisis económico y revolución liberal en España: Economistas académicos en las Cortes liberales, 1834-1874.
} 


\title{
THE SPANISH EXILES OF THE CIVIL WAR IN THE HIGH CENTERS OF ECONOMICS EDUCATION OF LATINAMERICA
}

\author{
Manuel Martín Rodríguez ${ }^{1}$ \\ Universidad de Granada - España \\ mmartinr@ugr.es
}

\begin{abstract}
At the end of the Spanish civil war (1936-39), many intellectual people were in the exile. In spite of that did not exist still in Spain high studies of Economy in those dates, enough of them became teachers of this discipline or being employers at centers of economic research. In this article it is very important to study the main contributions of this group, very little known till now, about the education and research of Economy in Latin America.
\end{abstract}

Key words: Exile, Spanish Civil War, Higher Education Economy. 


\section{INTRODUCCIÓN}

En 1939, al concluir la guerra civil española, aunque se estudiaba la asignatura de Economía en algunos centros superiores de enseñanza, no existían aun en la Universidad española Facultades de Economía y tampoco había, por tanto, titulados universitarios en Economía. Tal vez ello explique que, pese a que fueran numerosos los exiliados republicanos que terminaron ejerciendo como economistas académicos en los distintos países de acogida, no hayan sido apenas estudiados $^{2}{ }^{2}$ si se exceptúa el reciente trabajo de Martín Rodríguez y Fernández Clemente. ${ }^{3}$

Este trabajo, una apretada síntesis de una investigación que verá la luz en un libro de próxima aparición, ${ }^{4}$ no se dedica a todos los economistas del exilio republicano español de 1939 sino sólo a los que ejercieron como profesores en centros superiores de enseñanza de Economía en los distintos países de acogida de América Latina. Se divide en cuatro epígrafes: el primero se ocupa de los economistas exiliados en México, el país que acogió al mayor número de intelectuales y profesionales republicanos españoles; y los tres siguientes, de las Antillas, de Colombia y Venezuela, y de Argentina y Chile, respectivamente. Se añade una sucinta Bibliografía, en la que, para ajustar el texto a las normas de la revista, sólo se incluye una mínima parte de las referencias utilizadas.

\section{Los exiliados españoles y los estudios superiores de economía en México}

\section{El marco institucional de los estudios de Economía en México}

Según recientes estimaciones de Vilar, ${ }^{5}$ de los 59.000 exiliados de la guerra civil española en América Latina, algo más de la mitad fueron a México, con un

\footnotetext{
2 En la obra de Amo y Shelby. (1950): tan sólo aparecen clasificados como economistas Abrisqueta, Alienes, Sánchez Sarto y Vila Comaposada; en la obra colectiva sobre el exilio republicano dirigida por Abellán (1976) no se les concede ningún capítulo específico; en El exilio español en México (1982) apenas se les dedican unas páginas, confundidos con juristas y sociólogos, fándose importancia tan sólo a Sánchez Sarto, Sacristán y Márquez; y en el libro de Giral. (1994); sobre Ciencia española en el exilio, ni siquiera aparecen.

3 RODRÍGUEZ, Martín y FERNÁNDEZ CLEMENTE, E. (2009): "Sesenta economistas académicos del exilio de 1936-1939”, en: Fuentes Quintana (dir.) y Comín (ed.): Economía y economistas en la Guerra Civil, Barcelona, Galaxia GutenbergCírculo de Lectores-Real Academia de Ciencias Morales y Políticas.

4 El libro, con el título de Economistas académicos del exilio republicano español de 1939, aparecerá publicado en la editorial Toledo de Granada (España) (ISBN: 978-84937700-7-5)

5 VILA I COMAPOSADA, M.A. (1970): Geografia económica de Venezuela, Caracas, Monte Ávila Editores, C.A., p. 388.
} 
alto contingente de profesores y científicos. Al tiempo de su llegada, los estudios de Economía en este país se encontraban en una situación incipiente, muy similar a la tenían por ese mismo tiempo en España. Daniel Cosío, en compañía de un reducido grupo de intelectuales mexicanos que habían estudiado Economía en el extranjero, había conseguido en 1929 que se creara una Sección de Economía dentro de la Facultad de Derecho y Ciencias Sociales de la Universidad Nacional Autónoma de México (UNAM), ${ }^{6}$ que en 1934 se convirtió en la Escuela Nacional de Economía. La historia de La Casa de España-El Colegio de México, el segundo centro superior de enseñanza de Economía de México, a cuya creación tanto contribuyeron los exiliados republicanos españoles, es bien conocida. ${ }^{7} \mathrm{Y}$, después de algunas otras experiencias menores, ${ }^{8}$ en 1946 se crearía el Instituto Tecnológico Mexicano (ITM, luego ITAM), que se convirtió pronto en un centro de gran prestigio para la formación de economistas de empresa.

Junto a estos tres primeros centros, en los años setentas se fueron creando numerosos programas de Economía en distintos centros públicos y privados. El de mayor interés para nosotros es el Centro de Investigación y Docencia Económica (CIDE), ${ }^{9}$ creado en 1973 con fondos públicos para formar a los economistas que necesitaba el gobierno para sus programas de desarrollo económico.

A todos estos centros se incorporaron los exiliados españoles de 1939. En el próximo apartado nos ocupamos de los que Migallón llamó maestros españoles y en el siguiente de los economistas que llegaron a México siendo aún niños o nacieron en los primeros años de exilio de sus padres. ${ }^{10}$

\section{Maestros españoles en la universidad mexicana Javier Márquez: un economista de la London School of Economics}

Javier Márquez Blasco, estudió Derecho en la Universidad Central de

\footnotetext{
6 Un excelente análisis de la relación entre objetivos económicos del Estado e institucionalización de los estudios de Economía en México, en: BABB, S. (2001): Managing México. Economists from Nationalism to Neoliberalism, Princeton, Princeton University Press, p. 56.

7 LIDA, C.E.; MATESANZ, J.A., Y VÁZQUEZ, J.Z. (2000): La Casa de España y El Colegio de México. Memoria 1938-2000, México, El Colegio de México, p. 388.

8 LEWIS, W.A. (1952): La planeación económica, México D.F, Fondo de Cultura Económica.

9 MARTíneZ TARRAGO, T. (2005): "Orígenes y creación del CIDE: testimonio de la maestra Trinidad” en Revista Análisis Económico, vol. XX, nº 43, pp. 342-366.

${ }^{10}$ Eugenia Correa y Alicia Girón en el 2009 acaban de publicar una breve antología de textos de Sánchez Sarto, Álvaro de Albornoz de la Escosura, Serrano Migallón, Ramón Ramírez, Javier Márquez, Lara Beautell, Alfredo Lagunilla y Antonio Sacristán.
} 
Madrid e hizo estudios de postgrado en la École Livre de Sciences Politiques de París y en la London School of Economics (1934-35). A su llegada a México ejerció diversas actividades académicas en El Colegio de México, fue durante siete años subdirector de la editorial Fondo de Cultura Económica (FCE), fue codirector de la revista El Trimestre Económico, vinculada en esos primeros años a la editorial, y colaboró con el Banco de México.

Durante sus años en el FCE tradujo numerosos títulos de economía y fue profesor de Economía en El Colegio de México y de Teoría del Comercio Internacional en la Escuela Nacional de Economía de la UNAM, un tema al que dedicó sus primeros trabajos académicos. En el último de ellos, Inversiones internacionales de América Latina ${ }^{11}$ criticó la teoría clásica del comercio internacional y anticipó algunas de las ideas e instrumentos analíticos que servirían a Prebisch y los economistas de la Comisión Económica para América Latina (CEPAL) para explicar el subdesarrollo económico de América Latina y para elaborar su propio modelo de desarrollo para la región.

Al dejar el FCE en 1946 colaboró con el Banco de México, fue funcionario del Fondo Monetario Internacional en Washington (FMI) (1947-1951) y de la CEPAL en Santiago de Chile (1951) y dirigió durante veinte años el Centro de Estudios Monetarios Latinoamericanos (CEMLA) (1953-73), un centro de enseñanza e investigación creado en 1952 con el que las autoridades monetarias latinoamericanas trataron de intercambiar experiencias y de mejorar el conocimiento de los aspectos monetarios de sus economías. De su trabajo analítico en el campo monetario, que tuvo una gran influencia en toda la región, tal vez lo más representativo sea su libro Problemas del oro, ${ }^{12}$ publicado en 1969 cuando el FMI estaba creando los Derechos Especiales de Giro.

\section{Ramón Ramírez: alumno y profesor de la Escuela Nacional de Economía}

Ramón Ramírez Gómez (Madrid, 1913; México, 1972), maestro de primera enseñanza y presidente de la Federación Española de Trabajadores de la Enseñanza (FETE-UGT) en España, emigró a México en 1940, donde después de obtener el título de economista en la UNAM llegó a ser uno de sus más distinguidos catedráticos en los tiempos de su orientación marxista.

Después de obtener la cátedra de Teoría Monetaria y del Crédito en la Escuela Nacional de Economía en 1951, Ramírez centró su interés en estas materias.

\footnotetext{
11 MÁRQUEZ, J. (1945): Inversiones internacionales en América Latina, México, Banco de México, p. 98.

12 MÁRQUEZ, J. (1969): Problemas del oro, México, CEMLA, p. 123.
} 
Publicó diversas obras en las que defendió la tesis de que "los sistemas monetarios, más que instrumentos de desarrollo económico, son palancas en manos de los países poderosos para oprimir a los pueblos débiles, en cuyas economías tratan de influir a través de distintos métodos." ${ }^{33}$ En 1960 se integró en el Instituto de Investigaciones Económicas de la UNAM contribuyendo a la creación de su revista, Problemas del Desarrollo. Revista Latinoamericana de Economía.

Sus explicaciones de clase, aunque fueron dándose a los alumnos en forma de apuntes a partir de 1958, no conocieron una versión definitiva hasta poco después de su muerte, bajo el título de La moneda, el crédito y la banca a través de la concepción marxista y de las teorías subjetivas, ${ }^{14}$ de clara orientación marxista.

\section{Lagunilla Iñarritu: un economista singular}

Alfredo Lagunilla Iñarritu (Vizcaya, 1896; México, 1979) estudió Derecho y profesorado mercantil en España y obtuvo el título de diplomado en el Instituto de Economía Aplicada de Bruselas. Trabajó en el Banco de España y publicó un interesante libro, Nuevos Ensayos sobre El Capital, ${ }^{15}$ una interpretación cooperativista de la economía clásica y de la economía marxista.

Con este bagaje llegó a la República Dominicana, donde no pudo resistir su clima ni las funciones estrictamente productivas que el dictador Trujillo tenía reservadas para los exiliados republicanos, trasladándose a México donde, después de diversos trabajos en entidades bancarias y financieras, pasó a desempeñar los cargos de gerente del Departamento de Estudios Económicos de Valores del Banco de México y de profesor de Economía Monetaria y otras disciplinas económicas en el Instituto Tecnológico de México y en la Escuela Nacional de Economía de la UNAM. Póstumamente, en reconocimiento de sus méritos, el Banco de México patrocinó la publicación de su monumental obra, Historia de la banca y moneda en México. ${ }^{16}$

La producción científica de Lagunilla es copiosísima, casi toda ella sobre temas monetarios. En sus primeros años de exilio fue uno de los animadores de

\footnotetext{
13 Ibídem., p 56.

${ }^{14}$ RAMÍREZ GÓMEZ, R. (1972): La moneda, el crédito y la banca a través de la concepción marxista y de las teorías subjetivas, México D.F, UNAM, Instituto de Investigaciones Económicas.

${ }^{15}$ LAGUNILLA IÑARRITU, A. (1958): Desarrollo y equilibrio en la economía actual, Madrid, Aguilar, p. 134

${ }^{16}$ LAGUNILLA IÑARRITU, A. (1981): Historia de la banca y moneda en México, 2 vols., México, Editorial Jus, p. 90.
} 
las dos grandes revistas de economía mexicanas, El Trimestre Económico e Investigación Económica. De sus libros, destacan el Desarrollo y equilibrio de la economía mundial, ${ }^{17}$ en el que analizó la relación entre desarrollo y equilibrio económico, y Dinero y capital, ${ }^{18}$ en el que se ocupó del modelo de "financiación acelerada" del desarrollo económico que se había seguido en algunos países latinoamericanos.

\section{Sánchez Sarto: un economista aragonés en América Latina}

Manuel Sánchez Sarto (Zaragoza, 1897; México, 1980) estudió las licenciaturas de Derecho y de Letras en la Universidad de Zaragoza, cursó estudios en las Universidades de Munich, Kiel y Berlín (1921-22), fue director literario y gerente de la editorial Labor (1923-1939), tradujo para ella numerosas obras de política, sociología y economía y fue profesor de Historia Económica en la efímera Facultad de Ciencias Jurídicas, Políticas, Económicas y Sociales de la Universidad Autónoma de Barcelona. En 1939, aunque no había militado en ningún partido político, tuvo que exiliarse, primero en París y Nueva York y después en México, donde residió la mayor de su vida.

A su llegada a este país ejerció como director gerente de la editorial Atlante (1939-45), fundada por exiliados españoles, trabajó también en el Fondo de Cultura Económica, para el que tradujo a List, Cantillon y Weber, e impartió la asignatura de Historia Económica en la Escuela Nacional de Economía de la UNAM, de la que llegó a ser catedrático en 1956. Fue investigador en el Instituto de Investigaciones Económicas y subdirector de la revista Investigación Económica, en la que publicó algunos trabajos. Entre 1949 y 1953 fue profesor y Director del Departamento de Economía del México City College for the Leading Industrialists of México.

Invitado por Silva Herzog, fue asesor en la Dirección de Estudios Hacendarios de la Secretaría de Hacienda y Crédito Público (1940-45 y 194951), para la que hizo numerosos informes. Entre 1946 y 1949, invitado por el presidente Rómulo Gallegos, fue a Venezuela, donde trabajó como economista asesor de la Corporación Venezolana de Fomento y como profesor de Economía y Sociología en las Facultades de Economía y Ciencias Jurídicas de la Universidad de Caracas. A su vuelta fue asesor del Banco de México (1949-53), al que llevó a otros exiliados españoles, como el geógrafo Leonardo Martínez Echevarría, el ingeniero Rodríguez Mata y los economistas Alfredo Lagunilla y

\footnotetext{
${ }^{17}$ Ibídem., p.78.

${ }^{18}$ Ibídem., p.118.
} 
José Bullejos. A partir de 1950 fue economista asesor de la CEPAL en la subsede de México, manteniendo en ella importantes discrepancias con Prebish. Y entre 1953 y 1856 fue profesor en la Escuela Superior de Administración Pública de las Naciones Unidas para América Central (ESAPAC), creada por iniciativa de la CEPAL. ${ }^{19}$

\section{Sacristán Colás: un economista liberal, crítico con la economía liberal}

Antonio Sacristán Colás (Madrid, 1902; México D.F., 1986), catedrático de Derecho Mercantil en la Universidad de Madrid, fue diputado en las Cortes Constituyentes de la República y subsecretario de Hacienda. Al final de la guerra, tuvo que exiliarse en México.

Por su experiencia en cuestiones bancarias fue encargado por el gobierno mexicano de la elaboración de la Ley de Instituciones de Crédito de 1941, en la que se optó por una banca especializada con un mayor protagonismo de las sociedades financieras e hipotecarias. En febrero de 1940, él mismo constituyó con capital mexicano la Sociedad Mexicana de Crédito Industrial, una especie de banco industrial. Desde 1940 impartió clases en El Colegio de México y en la Escuela Nacional de Economía de la UNAM, desempeñando primero la cátedra de Teoría Monetaria y después la de Desarrollo Económico durante más de cuarenta años. A partir de la creación en 1964 de la Universidad Anáhuac, un centro superior de enseñanza privada, impartió en ella la asignatura de Desarrollo Económico.

En 1977 fue nombrado presidente del CIDE. Sus críticos le acusaron de hacer de este centro un foco de pensamiento económico liberal, pero de la lectura de sus libros no cabe deducir esto. Publicó numerosos trabajos en las colecciones del centro y en las revistas El economista mexicano e Investigación Económica, principalmente sobre teoría monetaria y desarrollo económico, y fue comentarista económico en el periódico El Heraldo.

De entre sus numerosos libros nos referiremos tan sólo a los dos que mejor recogen su pensamiento económico: en sus Principios esenciales del crecimiento económico ${ }^{20}$ criticó la economía neoclásica del desarrollo

\footnotetext{
19 PÉREZ OLEA, M. (1955): "La Escuela Superior de Administración Pública de América Central (ESAPAC)", en: Revista de Administración Pública, n 17 , pp. 317 -

338; LABERGE, E.P. (1962): "Esapac. A Regional Experiment in Public Administration Training”, en: Canadian Public Administration, vol. 5.3, pp. 305-311.

${ }^{20}$ SACRISTÁN COLÁS, A. (1973) (a): Principios esenciales del crecimiento económico, México, Juan Pablos Editores, p 123.
} 
económico y en Keynes ante la crisis mundial de los años ochenta, ${ }^{21}$ que escribió para denunciar los errores de la política económica mexicana en las crisis de 1976 y 1982, expuso su propia teoría económica. Para Sacristán, la política económica correcta no había que buscarla en los libros de economía sino que estaba en la propia Constitución de la revolución mexicana en la que se consagraba el principio de protección al trabajo, "con clara intuición de que sólo la remuneración del trabajo cuando es proporcional a su productividad constituye el verdadero motor del proceso económico, y sin que ello vaya en menoscabo siquiera de la participación de la ganancia, si ésta se conforma con ser proporcionada por el crecimiento del producto, sin promover la depreciación del salario." ${ }^{22}$ Y esto, en modo alguno podía conseguirlo sólo el mercado, por lo que era totalmente necesaria la intervención del Estado en la economía.

\section{Faustino Ballvé y sus "Diez lecciones de Economía”}

Faustino Ballvé Pallisé (Barcelona, 1887; México, 1958) es probablemente el economista español del siglo XX con mayor difusión internacional. Licenciado en Derecho en Barcelona, amplió estudios de economía en Berlín y Reino Unido. A su vuelta, abrió un bufete especializado en asuntos mercantiles e internacionales, publicó sobre algunos aspectos del socialismo y trabajó como traductor para diversas editoriales. Durante la República organizó y dirigió en Cataluña el partido Acción Republicana, siendo elegido diputado por esta formación en 1936. En 1939 tuvo que exiliarse, primero a Francia y luego a México. Aquí convalidó su título de abogado, abrió de nuevo despacho profesional y se dedicó a la docencia de la Economía: en la UNAM fue profesor de Economía en la Facultad de Derecho y en el Instituto Tecnológico de México (ITAM), profesor de Economía.

En 1942 conoció a Mises, que había sido invitado por Montes de Oca, exdirector del Banco Central de México, para impartir unas conferencias en la capital de la República. ${ }^{23}$ Su mensaje liberal entusiasmó a Ballvé. Facilitada por el idioma común alemán, se estableció entre ambos una gran amistad personal e intelectual que marcó profundamente la orientación del exiliado español. Fruto

\footnotetext{
${ }^{21}$ SACRISTÁN COLÁS, A. (1985) (b): Keynes ante la crisis mundial de los años ochenta, México, D.F, Siglo Veintiuno Editores.

22 Ibídem. (b), p.147.

${ }^{23}$ A mediados de 1943 Mises fue invitado de nuevo por empresarios mexicanos a elaborar un informe sobre la economía de México. Una edición en español, con el título de Problemas económicos de México, ha sido publicada recientemente por el Instituto Cultural Ludwig von Mises de México.
} 
de ello fueron sus Diez Lecciones de Economía, ${ }^{24}$ uno de los actuales iconos de la economía austriaca, con traducciones al francés y al inglés. ${ }^{25}$

\section{Eligio de Mateo y José María Urbano}

Junto a los seis anteriores, debemos citar al menos a otros dos economistas exiliados españoles. Eligio de Mateo Souza (Madrid, 1908), licenciado en Ciencias Químicas y perito mercantil por la Universidad de Madrid, llegó a México en 1939 triunfando años después como empresario al frente de una empresa de productos químicos, Mateo y Cia S.A.. Además fue profesor de Comercio Internacional, Macroeconomía y Política Económica de México en la Facultad de Comercio y Administración de la UNAM (1972-81), colaboró en diversas revistas de economía (Actividad económica en Latinoamérica y Mexican-American Review), publicó libros y fue presidente del Consejo Nacional de la Industria Química y Para química

José María Urbano Guerrero (Granada, 1882; México, 1946), doctor en Derecho por la Universidad de Madrid, amplió estudios en las Universidades de Heidelberg y París, especializándose en Economía. Llegó a México en 1939, ejerciendo como profesor de Historia de las Doctrinas Económicas en la Escuela Nacional de Economía de UNAM hasta su temprana muerte en 1946. Publicó artículos de economía en distintas revistas y tradujo el primer tomo de El apogeo del capitalismo de Werner Sombart para el Fondo de Cultura Económica.

\section{Los hijos del exilio}

Rafael Izquierdo González (1928) estudió Economía en la UNAM. Durante unos años trabajó en la CEPAL y en los años sesentas fue asesor del Secretario de Hacienda y Crédito Público y del presidente de la República, formando parte del Grupo Secretaría de Hacienda-Banco de México. Fruto de esta experiencia fue su libro Política hacendaria del desarrollo estabilizador, 1958-1970. ${ }^{26}$ Después de dejar su trabajo en la Secretaría de Hacienda fue asesor de inversiones extranjeras del presidente López Portillo y consejero del

\footnotetext{
${ }^{24}$ BALLVÉ, F. (1956): Diez Lecciones de Economía, México, D.F., Instituto de Investigaciones Sociales y Económicas, p. 234.

${ }^{25}$ La primera traducción inglesa fue publicada por la editorial Van Nostrand (The Essentials of Economics, Princeton 1963), a la que siguió luego la de Arthur Goddard (Foundation for Economic Education, 1994). En Francia, su traductor fue Raoul Audouin, una de las grandes figuras del liberalismo francés del siglo XX.

${ }^{26}$ IZQUIERDO, R. (1995): Política hacendaria del desarrollo estabilizador, 19581970, México, D.F., Fondo de Cultura Económica, p. 45.
} 
Banco de México. Cuando decidió desvincularse de la administración pública, pasó a ser socio de AFH Consultores Asociados S.C. También fue economista de la Universidad de las Américas y de la Universidad McGill, de Canadá.

ÁlvaroAlbornoz de la Escosura (1936), nieto de Álvaro de Albornoz, ministro de la República y presidente del gobierno republicano en el exilio, llegó a México al terminar la guerra civil. Estudió en la Escuela Nacional de Economía de la UNAM (1954-58), hizo cursos de postgrado en Francia (1959-61) y obtuvo el Premio Nacional de Economía en 1965. Su brillante carrera profesional se ha desarrollado en el Banco de México, Banco Nacional de Crédito Ejidal, Secretaría de Hacienda y Crédito Público, Banco Nacional de Crédito Agrícola y diversas empresas estatales. Asiduo conferenciante y asistente a congresos científicos nacionales e internacionales, es autor de valiosas publicaciones, casi todas ellas relacionadas con la agricultura y el crédito

Trinidad Martínez Tarrago cursó la licenciatura en Economía en la Escuela Nacional de Economía de la UNAM (1951-56) y el postgrado en la Universidad de Glasgow (Escocia). A su vuelta trabajó en la Secretaría de Hacienda y Crédito Público (1955-59) y fue profesora adjunta de la asignatura Ciclos Económicos en la Escuela Nacional de Economía (1958). En 1963 se fue de nuevo al Reino Unido. Al finalizar el curso 1970-71 decidió regresar, aceptando primero una oferta de Universidad católica de Anáhuac (México D.F.) para reorganizar la Escuela de Economía, y cuando se creó el CIDE en 1974, dirigió su área de docencia y después el propio centro. En estos años, Martínez Tarrago trabajó con Fernando Fajnzylber en la redacción de Las empresas transnacionales ${ }^{27}$ una obra clásica en la literatura latinoamericana sobre empresas transnacionales. La llegada a la presidencia del CIDE de Antonio Sacristán Colás, con el que mantuvo unas difíciles relaciones, le llevaron a dejarlo en 1983.

Pedro Bosch García (Barcelona, 1922) llegó a México en 1941 con su padre, el historiador Pedro Bosch Gimpera. Nacionalizado mexicano, se licenció en la Escuela Nacional de Economía de la UNAM e hizo estudios de postgrado en la American University de Washington. A su vuelta tuvo una brillante carrera como economista: organizó el Departamento de Economía del México City College, fue profesor de Economía de la UNAM, economista de la Oficina de Investigaciones Industriales del Banco de México, miembro del consejo de

\footnotetext{
${ }^{27}$ FAJNZYLBER, F. y MARTÍNEZ TARRAGO, T. (1976): Las empresas transnacionales. Expansión a nivel mundial y proyección de la industria mexicana, México D.F., Fondo de Cultura Económica, p. 23.
} 
administración de varias empresas públicas y miembro de la delegación oficial mexicana en las conferencias generales del Tratado de Montevideo.

Antonio Gazol Sánchez, hijo del jurista y economista Antonio Gazol Santafé, ${ }^{28}$ se licenció en Economía en la Facultad de Economía de la UNAM en 1966. Al terminar sus estudios fue funcionario del gobierno federal, ejerciendo entre otros cargos el de Director del Instituto Mexicano del Café. Durante treinta y cinco años fue profesor de Economía y de Historia Económica en la Facultad de Economía de la UNAM. Ha publicado varios libros y ha escrito en revistas de divulgación económica y en prensa diaria. Ha sido presidente del Colegio Nacional de Economistas de México.

Carlos Marichal Salinas, hijo del ensayista e historiador Juan Marichal y nieto del poeta Pedro Salinas, ambos exiliados, nació en Estados Unidos en 1948, donde residían entonces sus padres. En 1977 obtuvo el Ph.D. en la Harvard University, Department of History. Después ha sido profesor titular y coordinador de la Maestría en Historia en la UAM-Iztapalapa (México) (1979-89) y profesorinvestigador del Centro de Estudios Históricos de El Colegio de México.

Javier Márquez Diez-Canedo (México D.F., 1940), hijo de Javier Márquez, es Ingeniero Mecánico en el Instituto Tecnológico de Monterrey (1959-65), M. Sc. en la London School of Economics (1965-67), Ph. D. en Ciencias Matemáticas en la Johns Hopkins University (1970-73) y Diplomado en Banca Central y Política Monetaria en el CEMLA (1976). Ha hecho la mayor parte de su carrera en el Banco de México, donde actualmente es Gerente de Análisis de Riesgos y Proyectos Especiales. Ha elaborado numerosos documentos de trabajo en el seno del CEMLA, algunos de ellos publicados en su Revista Monetaria y en su colección de Ensayos, y para el Banco de México, la mayor parte de ellos sobre riesgos financieros.

Carlos Roces Dorronsoro (México, 1945-2003), hijo de Wenceslao Roces, ha sido una de las figuras más singulares del exilio republicano español. Licenciado en Economía en la Escuela de Economía de la UNAM, hizo un master en la London School of Economics y a su vuelta fue profesor de Economía en El Colegio de México durante casi treinta años, hasta su muerte en 2003. De su madre, la actriz Carmen Dorronsoro, que trabajó en algunas películas de

\footnotetext{
${ }^{28}$ Antonio Gazol Santafé, profesor en la Facultad de Derecho, ha sido tenido también por economista en México. Aparte sus publicaciones, ha colaborado con sucesivos gobiernos mexicanos en distintas responsabilidades.
} 
Buñuel, heredó la pasión por el arte, llegando a tener gran éxito en el diseño de figurines para el teatro.

Emilio Sacristán Roy, hijo de Antonio Sacristán Colás, es maestro por la Universidad de Columbia y licenciado en Economía por la Universidad de Harvard. Comenzó su carrera docente en la Facultad de Economía de la UNAM como profesor adjunto del profesor Ricardo Torres Gaitán en la asignatura Comercio Internacional. Desde 1963 ha sido profesor de Macroeconomía en esta misma Facultad, y desde 1988 profesor de Finanzas en el Instituto Nacional de Administración Pública, en el que dirige actualmente el Programa de Alta Dirección de Entidades Públicas. Trabajó con su padre en el CIDE. Desde 1993 es miembro de la Academia Mexicana de Economía Política, de la que ha sido presidente. Junto a su trabajo académico ha desarrollado una brillante carrera en la administración pública y en la empresa pública y privada.

Matilde Souto Mantecón, nieta de José Ignacio Mantecón, ${ }^{29}$ profesora de la UNAM e investigadora en el Instituto de Investigaciones Dr. José María Luís Mora, es una de las más brillantes historiadoras económicas de México y cuenta ya con importantes publicaciones.

Jaime Serra Puche (México, 1951), nieto de Jaime Serra Hunter, catedrático de Historia de la Filosofía y rector de la Universidad de Barcelona (1931-33), y de José Puche Álvarez, catedrático de Fisiología y rector de la Universidad de Valencia, cursó la maestría en Economía en El Colegio de México y se doctoró en Economía en la Universidad de Yale. En diferentes etapas de su vida ha sido profesor de Economía en El Colegio de México, en las Universidades de Stanford y Princeton y en la New Yory University. Pero donde más ha destacado ha sido en el campo de la política. Después de haber ocupado diversos cargos durante la presidencia de Miguel de la Madrid, fue Secretario de Comercio y Fomento Industrial durante el sexenio de Carlos Salinas de Gortari (1988-94). En 1994 se llegó a pensar que podría ser presidente de la República en unas elecciones en las que finalmente fue promovido Ernesto Zedillo, quien le nombró Secretario de Hacienda y Crédito Público, cargo en el que permaneció tan sólo 28 días, por la grave crisis económica desatada con ocasión del llamado "error de diciembre”. En 1979 recibió el Premio Nacional de Economía por el conjunto de sus publicaciones.

\footnotetext{
29 José Ignacio Mantecón (Zaragoza, 1902; México 1982), llegó a México en 1941 y trabajó como investigador en El Colegio de México hasta 1945. Desde esta fecha fue catedrático en la recién creada Escuela Nacional de Bibliotecarios y Archivistas de México.
} 


\section{Las Antillas}

\section{República Dominicana: un lugar de acogida y de tránsito}

La República Dominicana, pese al régimen feudal de Trujillo, fue uno de los tres países, junto a México y Chile, que acogió colectivamente a los republicanos españoles. Según recientes estimaciones de Juan B. Vilar, ${ }^{30}$ en 1939 debieron llegar a este país en torno a 5.000 españoles.

La recién creada Facultad de Filosofía y Letras en la vieja Universidad de Santo Domingo acogió a algunos de estos exiliados, pero entre ellos sólo estuvieron durante algún tiempo los economistas Alfredo Lagunilla y Gabriel Franco. Años más tarde, sin embargo, Eduardo Latorre Rodríguez (Santo Domingo, 1941-2003), hijo de exiliados y Ph.D. en Ciencias Políticas en la Columbia University de New York (1972), ejercería una destacadísima labor académica. Fue profesor de Economía en la Universidad Católica Madre y Maestra de Santo Domingo (1967-69) y en la Universidad Autónoma de Santo Domingo (1971-76). En 1972 fundó el Instituto Tecnológico de Santo Domingo (INTEC), una universidad privada en la que fue profesor (1972-82) y rector (1976-84). Y ese mismo año comenzó una exitosa carrera política que le llevaría a la Secretaría de Estado de Relaciones Exteriores de la República Dominicana entre 1996 y 2000, durante la presidencia de Leonel Fernández.

\section{Cuba: Julián Alienes Urosa y Anastasio Mansilla}

No fue muy acogedora Cuba con los intelectuales republicanos españoles. El único economista español que permaneció en la isla durante casi veinte años fue Julián Alienes Urosa (Madrid, 1909-2007), Intendente Mercantil por la Escuela Superior de Comercio de Madrid. Después de otras ocupaciones menores, la Cámara de Comercio de la República de Cuba le ofreció un trabajo acorde con su formación, para elaborar estudios económicos en su servicio de estudios. Desde la propia Cámara partió la idea de crear el Banco Nacional de Cuba, dándose el encargo a Alienes de hacer los correspondientes estudios económicos y de defender el proyecto de ley en el Senado. En 1948, creado el Banco, fue llamado a dirigir su servicio de estudios, donde publicó su obra más importante, Características Fundamentales de la Economía Cubana, ${ }^{31}$ un lúcido análisis

\footnotetext{
${ }^{30}$ VILAR, J.B. (2006): La España del exilio. Las emigraciones políticas españolas en los siglos XIX y XX, Madrid, Editorial Síntesis, p. 388.

${ }^{31}$ ALIENES UROSA, J. (1950): Características fundamentales de la economía cubana,

La Habana, Banco Nacional de Cuba, p. 256.
} 
de la economía cubana, de inspiración keynesiana, que los economistas de la revolución castrista discuten todavía. ${ }^{32}$

Anastasio Mansilla, uno de los niños de la guerra civil española llevados a Rusia, que llegó a ser profesor de Economía Política en la Universidad de Lomonosov en la Unión Soviética, fue enviado a La Habana cuando a los pocos años del triunfo de la revolución Castro solicitó un profesor para que enseñase economía marxista a todo el Consejo de Ministros en un seminario de seis meses. ${ }^{33}$ Mansilla utilizó para su trabajo la traducción de El Capital de Wenceslao Roces y él mismo publicó, para uso de sus alumnos, unos Comentarios a la sección séptima del Tomo I de El Capital. ${ }^{34}$

\section{Puerto Rico: Gabriel Franco}

La mayor parte de los profesores españoles exiliados en Puerto Rico tuvieron oportunidad de enseñar en su Universidad. De todos ellos, el único economista fue Gabriel Franco (Astorga, 1897; Madrid, 1968), catedrático de Economía Política y Hacienda Pública de la Universidad de Murcia. Militante de Izquierda Republicana, en febrero de 1936 fue nombrado Ministro de Hacienda, cargo del que dimitió tres meses después por discrepancias con la política económica del gobierno. Al concluir la guerra civil tuvo que exiliarse, primero en México, donde fue profesor de la Escuela Nacional de Economía de la UNAM, y a partir de 1945 en San José de Puerto Rico, donde ejerció como catedrático de Ciencias Empresariales en la Universidad de Río Piedras.

\section{Colombia y Venezuela}

\section{Abrisqueta: un economista y empresario polifacético en Colombia}

En 1934, después de medio siglo en la oposición, había llegado al poder el grupo liberal dirigido por Alfonso López Pumarejo, quien puso entre sus prioridades políticas la educación. Gracias a ello, pese a que la mayoría de los exiliados que llegaron a Colombia se trasladaron pronto a otros países, hubo oportunidades en la docencia e investigación para todos los que se quedaron.

\footnotetext{
32 La economista e historiadora Nélida Lamelas (1990) ha visto a Alienes como un "representante de los intereses del capitalismo de Estado, que implementó los mecanismos de reactivación de la economía capitalista frente al socialismo".

${ }^{33}$ BORREGO DÍAZ, O. (2001): Che Guevara, el camino del fuego, Buenos Aires, Editorial Hombre Nuevo, p. 85.

${ }^{34}$ MANSILlA, A. (1965): Comentarios a la sección séptima del Tomo I de El Capital, La Habana, Publicaciones Económicas, p. 145.
} 
El que permaneció durante más tiempo y el que hizo un trabajo más brillante fue Francisco de Abrisqueta (Bilbao, 1913-1985), licenciado en Economía en la Universidad Comercial de Deusto. A la caída del frente vasco en 1937, se vio obligado a exiliarse en Colombia, donde encontró una excelente acogida gracias a un primer contrato de trabajo para la Contraloría General de la República que le facilitó la familia Ricaurte, uno de cuyos hijos había sido su compañero de estudios en España. En 1940 fundó con esta misma familia la empresa IRAL (Industrias Ricaurte y Abrisqueta, Limitada), dedicada a la troquelería y matrices, para la que llevó técnicos y obreros especializados vascos.

Fue director del Centro de Investigaciones Económicas de la Contraloría General de la República, profesor de Estadística en la Universidad Nacional de Colombia (1938-1945) y de Economía en la Universidad Javeriana, jefe de redacción de El Mes Financiero y Económico y asesor técnico de la Sección de Investigaciones Económicas del Banco de la República. ${ }^{35}$ En la Contraloría General de la República creó el servicio general de Estadística de Colombia e hizo numerosos estudios socioeconómicos sobre la clase obrera del país. En 1945 fue llamado por Alberto Lleras Camargo, expresidente de Colombia y por entonces representante de su país en la Unión Panamericana para dirigir su Instituto de Estadística en Washington

\section{La estancia en Venezuela de Vandellós y Joan Sardá}

A la muerte en 1935 de Juan Vicente Gómez, que había regido dictatorialmente los destinos de Venezuela durante casi treinta años, el país hizo una reforma constitucional en la que se diseñó un modelo económico en el que se favorecía la intervención económica del Estado a fin de contribuir a la aceleración del desarrollo económico del país. Para colaborar en esta nueva etapa se pensó en la contratación de economistas en Europa, entre los que estuvo el español Joseph Antoni Vandellós (Gerona, 1899; Nueva York, 1950), por entonces director del Institut d'Investigacions Econòmiques de Barcelona. ${ }^{36}$ En Venezuela, junto a las funciones para las que había sido contratado, que eran las de creación del Servicio Nacional de Estadística, impartió un curso de Estadística en la Universidad Central y unos seminarios de Geografía Económica en la Escuela Diplomática del Ministerio de Relaciones Exteriores.

\footnotetext{
${ }^{35}$ En 1945 se había creado un Instituto de Ciencias Económicas, adscrito a la Facultad de Derecho de la Universidad Central, que años después se convertiría en la primera Facultad pública de Ciencias Económicas del país. La Universidad Javeriana contaba desde 1933 con una Facultad de Ciencias Económicas y Jurídicas (Herrera y Low).

${ }^{36}$ PASCUAL, J. (1975): Un economista catalán: José Antonio Vandellós Sola (18991950), tesis doctoral, Universidad de Barcelona, p. 178.
} 
Después del golpe de Estado de octubre de 1945, aquejado también de problemas de salud, decidió marcharse como experto de la ONU a Estados Unidos, con residencia en Nueva York

En parecidas circunstancias a las de Vandellós también estuvo en Venezuela el economista Joan Sardá Dexeus. Tras obtener la cátedra de Economía Política y Hacienda Pública de la Facultad de Derecho de la Universidad de Santiago, en 1951 solicitó la excedencia para irse a Caracas como profesor de Teoría Económica de la Universidad Central y como asesor del Banco Central, donde permaneció con alguna breve interrupción hasta 1955.

\section{Sánchez Covisa: un economista liberal en Venezuela}

Joaquín Sánchez-Covisa Hernando (Madrid, 1915; Caracas, 1974) comenzó la licenciatura de Derecho en la Universidad de Madrid. Tras luchar en el frente de Madrid y servir en la Secretaría privada del presidente de Gobierno, Juan Negrín, marchó al exilio con su padre, catedrático de la Facultad de Medicina. En 1941 terminó la carrera de Derecho en la Universidad Central de Venezuela, en la que se doctoró más tarde en Ciencias Políticas. En 1944 fue nombrado profesor de Economía Política y más tarde de Derecho Internacional Privado de esta misma Universidad. Entre 1946 y 1951 fue profesor de Economía General, Teoría Económica y Teoría Monetaria en la Escuela de Ciencias Económicas y Sociales de la Universidad Central de Venezuela, creada en 1939. ${ }^{37}$ En 1970 dejó la cátedra para dedicarse con mayor intensidad a la investigación y a sus ocupaciones privadas.

En 1961, junto al venezolano Nicomedes Zuloaga y con el apoyo de la familia Cisneros, fundó y presidió el Instituto Venezolano de Análisis Económico y Social, precursor de Cedice, que editó durante años la prestigiosa revista Orientación Económica (1961-1973), con difusión en toda América Latina, de la que Sánchez Covisa fue su director y principal colaborador. En 1965, con el periodista venezolano Carlos Ball, fundó el periódico La Verdad para hacer frente a la apabullante hegemonía de la prensa izquierdista en esos años. Firme defensor de la economía de mercado, desarrolló una importante labor asesora en la Cámara de Industriales, en la Cámara de la Construcción, en C.A. La Electricidad de Caracas, en Sandoz de Venezuela y en la Fundación Rojas

\footnotetext{
${ }^{37}$ Sobre la creación de los estudios de Economía en la Universidad Central de Venezuela y el papel desempeñado por los españoles, vid. Martín Frechilla (2006). Además de los citados en el texto, también estuvieron en Venezuela y enseñaron en su Universidad los estadísticos españoles Antonio Repiso Granados, Francisco Azorín Poch, Bernardo Ferrán y Sixto Ríos García.
} 
Astudillo. Entre sus libros de economía destaca Economía, mercado y bienestar $^{38}$, una recopilación de sus editoriales en Orientación Económica y otros escritos, que en realidad era un libro de texto de Economía Política para estudiantes de Derecho con una clara inspiración en Röpke, al que añadió un análisis de los modelos de desarrollo económico y de integración regional de América Latina. En estos últimos veía el peligro de que pudieran conducir a una política de excesivo proteccionismo regional que aislara el mercado latinoamericano del resto del mundo. ${ }^{39}$

\section{Vila y Comaposada y la familia Pi y Sunyer en Venezuela}

Marc-Aureli Vila i Comaposada (Barcelona, 1908-2001) llegó a Caracas en 1943. En el curso académico 1945-46 fue nombrado profesor de Geografía Económica en la Facultad de Economía, con un contrato anual que se le fue renovando hasta que en 1950 se le reconoció la categoría de profesor asociado. En los años siguientes compartió la docencia de esta asignatura con la de Geoeconomía General y de Venezuela en la Universidad Católica Andrés Bello y con la dirección de la Unidad de Geografía de la Corporación Venezolana de Fomento.

Carles Pi i Sunyer llegó a Venezuela en 1952 a la edad de 64 años, contratado para organizar la Comisión Venezolana de Normas Industriales (COVENIN), después de haber realizado otros trabajos para el gobierno venezolano en el Reino Unido, donde había estado exiliado hasta entonces. Sin embargo, no se limitó a ello sino que tuvo una vida muy activa hasta su muerte en 1971, escribiendo para las mejores revistas del país, dando clases en la Facultad de Economía de la Universidad Central e interesándose por la economía venezolana, sobre la que publicó algunos buenos trabajos.

\section{Argentina y Chile}

\section{Argentina: una universidad cerrada para los exiliados españoles}

Desde el comienzo de la guerra civil, el gobierno argentino fue muy reacio a acoger a exiliados españoles, aunque poco a poco esta actitud se fue atenuando hasta llegar a ser el segundo país de acogida de republicanos después de México,

\footnotetext{
38 SANCHEZ-COVISA HERNANDO, J. (1974): Economía, mercado y bienestar.

Estudios económicos. Selección y ordenación póstumas, Caracas, Talleres de Cromotip,

p. 12 .

39 En apoyo de esta idea, Sánchez-Covisa citaba la obra The Customs Union Issue de J.

Viner (1950), de la escuela austriaca.
} 
con unos 10.000 exiliados. ${ }^{40}$ Para todos cuantos llegaron hubo oportunidades en distintas actividades económicas, incluida la industria editorial, ${ }^{41}$ pero fueron muy difíciles para los que intentaron enseñar en las principales Universidades del país.

\section{Prados Arrarte}

Jesús Prados Arrarte (Bilbao, 1909; Madrid, 1983) estudió Derecho y Profesorado Mercantil, obteniendo muy joven la cátedra de Economía Política y Hacienda Pública de la Universidad de Santiago. Al terminar la guerra civil se exilió en Argentina, donde permaneció hasta 1951. En estos años, aunque no pudo ejercer la docencia en la Universidad, trabajó en distintos centros de investigación. Su obra más ambiciosa de este tiempo fue Problemas básicos de la doctrina económica, ${ }^{42}$ en la que abordó con originalidad las grandes cuestiones económicas de su tiempo. En 1952 aceptó un contrato como "senior economist" de la CEPAL en su sede en Santiago de Chile.

\section{Serra i Moret}

Manuel Serra i Moret (Vic, 1884; Perpiñá, 1963), hijo del historiador José Serra, estudió en Barcelona. Después, con abundantes medios de fortuna, viajó y amplió sus estudios de economía y ciencias sociales en Estados Unidos e Inglaterra. En 1908 contrajo matrimonio en Argentina con la conocida escritora Sara Llorens y Carreres, permaneciendo en este país varios años (1908-1912). Luego regresó a España, donde inició una activa vida política. En 1939 formó parte del exilio republicano, primero en Francia, luego en Nueva York y finalmente en Argentina, donde sus lazos familiares le permitieron llevar una vida relativamente confortable, con frecuentes viajes por Europa y países latinoamericanos, en los que dictó conferencias e impartió cursos. En 1947 se instaló en París, y a partir de 1950, con problemas de salud, vivió en Perpiñán (Francia).

En Argentina fue uno de los fundadores de la Societat Catalana d'Estudis Politics, Econòmics y Socials y archivero del prestigioso diario de Buenos

\footnotetext{
40 SCHWARZSTEIN, D. (1998): “Actores sociales y política inmigratoria en la Argentina. La llegada de los republicanos españoles”, Exils et migrations ibériques vers l'Amerique Latine, $\mathrm{n}^{\mathrm{0}}$ 5, París.

${ }^{41}$ La gran editorial del exilio español en Buenos Aires fue Losada, fundada en 1938 por Gonzalo Losada, que había llegado unos años antes para ponerse al frente de la sucursal de la editorial Espasa Calpe.

${ }^{42}$ PRADOS ARRARTE, J. (1950): Problemas básicos de la doctrina económica, Buenos Aires, p. 54.
} 
Aires Noticias Gráficas. Aparte sus numerosos artículos en la prensa catalana del exilio, su libro más importante fue el Diccionario económico de nuestro tiempo. ${ }^{43}$

\section{Abraham Guillén}

Abraham Guillén (Guadalajara, 1913-1993) es internacionalmente conocido por su libro Estrategia de la guerrilla urbana, ${ }^{44}$ fuente de inspiración de guerrilleros de todo el mundo. Es menos conocido su trabajo como economista en varios países latinoamericanos, principalmente Argentina. En la etapa de Perón, fue editor de la revista Economía y Finanzas y articulista en el periódico El laborista, de Buenos Aires. Inmediatamente después del triunfo de la revolución castrista estuvo en Cuba durante algún tiempo. De vuelta a Argentina, fue encarcelado durante unos meses, solicitando luego asilo político en Uruguay, donde fue asesor económico de la Universidad del Trabajo y tomó contacto con elementos revolucionarios. Durante los años siguientes continuó publicando en el diario Acción, de Montevideo. Después vivió algún tiempo en Perú, donde fue experto internacional de la OIT en economía autogestionaria y desarrollo cooperativo, escribiendo en distintos medios y publicando nuevos libros.

A su regreso a España, ejerció como profesor en el Instituto Intercultural para la Autogestión y la Acción Comunal (INAUCO) y publicó sus dos libros mayores de economía, en los que legó todo su pensamiento, entre libertario y marxista: Economía libertaria y Economía autogestionaria.

\section{Nicolás Sánchez Albornoz.}

Nicolás Sánchez Albornoz (Madrid, 1926) formó parte del exilio antifranquista de la postguerra. Su larga peripecia de exiliado es bien conocida. Después de concluir la licenciatura en Historia en la Universidad de Buenos Aires, su carrera académica comenzó en la Universidad del Litoral, de Rosario (1955-66), en la que dirigió el Instituto de Investigaciones Históricas y fue secretario de la revista Desarrollo Económico, y continuó luego en las Universidades de Bahía Blanca (1957), La Plata (1958-63) y Buenos Aires (1963-66). Estuvo becado en París, donde asistió a los seminarios de Braudel, Pierre Vilar y Ernest Labrousse.

\footnotetext{
${ }^{43}$ SERRA MORET, M. (1944): Diccionario económico de nuestro tiempo, Buenos Aires, Mundo Atlántico, p. 14.

${ }^{44}$ GUILLÉN, A. (1956): La conspiración de la oligarquía o la Radiografía del Plan Prebisch, Buenos Aires, Edit. Guitem (Imp. La Técnica impresora).
} 
El golpe militar del general Ongania en 1966 le hizo renunciar a todos los cargos que ocupaba en Argentina en señal de protesta. Esta vez emigró a Estados Unidos, donde en 1968 se incorporó a la New York University, de la que fue catedrático titular de Historia hasta su nombramiento como profesor emérito en 1992. Durante estos años fue también profesor visitante en las Universidades de Austin (Texas) (1965), Yale (1969-70), Columbia (1971-72) y Carlos III (Madrid).

\section{Chile: los exiliados españoles y la CEPAL}

La República de Chile estaba gobernada desde 1938 por una conjunción frentepopulista, bajo la presidencia de Pedro Aguirre, con buena predisposición a aceptar a los refugiados españoles. Sin embargo, la cerrada resistencia de las asociaciones empresariales y de los sindicatos a la entrada de inmigrantes hizo que estos buenos propósitos se limitaran finalmente a la aceptación de una única expedición colectiva, la del Winnipeg, último buque que abandonó Francia antes de declararse la Segunda Guerra Mundial.

Años después, la creación de la CEPAL en 1948, con sede en Santiago, convirtió a la capital chilena en el think-tank del pensamiento económico de toda la región, en el que los exiliados españoles jugaron un papel destacadísimo. A partir de la creación de su subsede de México en 1951, las oportunidades para los que vivían aquí aumentaron considerablemente. Más tarde, en parte para atender a sus propias necesidades internas y en parte para defenderse de las críticas de que no era más que un organismo al servicio de las políticas gubernamentales sin soporte científico, la CEPAL, bajo los auspicios de la UNESCO, crearía el Instituto Latinoamericano de Planificación Económica y Social (ILPES) y la Facultad Latinoamericana de Ciencias Sociales (FLACSO), ambos con sede también en Santiago de Chile, que atraerían nuevas oleadas de profesores de toda América Latina, entre ellos algunos exiliados españoles. ${ }^{45}$

Manuel Medina Echavarría (Castellón, 1903; Santiago de Chile, 1977), a quien ya hemos encontrado en México, había estudiado Derecho en las Universidades de Valencia y Madrid y en la Universidad de Marburgo (Alemania), en la que se había familiarizado con el historicismo. Su incorporación a la CEPAL, invitado por Prebisch, a quien había conocido en México a principios de los cuarentas, tuvo lugar en 1952, pero sus funciones se limitaron durante años a ejercer como editor hasta que fue nombrado primer director de la Escuela

\footnotetext{
${ }^{45}$ Entre la abundante bibliografía sobre este la CEPAL, pueden citarse CEPAL (1998), Rodríguez (1981) y Hodara (1987).
} 
de Sociología de la FLACSO (1957-58). En 1963 se incorporó al ILPES como director de su División de Desarrollo Social, en el que permaneció ya hasta su jubilación en junio de 1974.

Los trabajos de Medina Echavarría para la CEPAL sobre los aspectos sociológicos del desarrollo económico no dieron comienzo hasta que Prebisch y sus primeros colaboradores se aplicaron al análisis concreto de las distintas economías latinoamericanas, comprobando su dualismo interno, su incapacidad para dar empleo a los excedentes de población agraria y los graves problemas que se generaban en los suburbios de las ciudades por la recepción de estos excedentes. ${ }^{46}$ La formación de Medina Echavarría y su profundo conocimiento de la sociología hacían de él el candidato perfecto para estudiar estos problemas y contribuir al estructuralismo cepalino desde esta perspectiva y a ello se dedicó a partir de 1957. ${ }^{47}$ Prebish, Cardoso, Falletto, Pinto, Urquidi, Sunkel, Iglesias y otros insignes hombres de la CEPAL han coincidido después en señalar la relevancia de sus aportaciones en la elaboración de su programa de desarrollo económico para América Latina. ${ }^{48}$

La CEPAL atrajo también a otros exiliados españoles. Uno de ellos fue Sánchez Sarto, muy crítico con sus ideas germinales sobre el desarrollo económico y sobre la integración regional, según vimos. El que tuvo mayor continuidad en el organismo internacional fue Cristóbal Lara Beautell (Santa Cruz de Tenerife, 1919), quien después de trabajar en el FCE (1945-47), ${ }^{49}$ en 1952, a propuesta de Urquidi, ${ }^{50}$ inició su colaboración, llegando a ser director de la subsede de México, director general de estudios y desarrollo regional, director de los trabajos que dieron lugar a la constitución del Mercado Común Centroamericano y director del ILPES. Francisco Giner de los Ríos Morales (Madrid, 1917), ${ }^{51}$ aunque no era economista hizo traducciones de economía

\footnotetext{
${ }^{46}$ La mayor parte de estas aportaciones de Medina Echavarría se publicaron en documentos oficiales de la CEPAL.

${ }^{47}$ A Love (2004), historiador y director de Latin American Studies, no le ha pasado desapercibida la relación entre el estructuralismo de la CEPAL y las ideas de los becarios de la Junta de Ampliación de Estudios en Alemania, entre los que estaba Medina Echavarría.

${ }^{48}$ En los escritos de todos ellos hay numerosas referencias elogiosas a Medina Echavarría, pero véase, por todas, CARDOSO, F.H. et al. (1982): Medina Echavarría y la sociología latinoamericana, Madrid, Ediciones Cultura Hispánica.

${ }^{49}$ Fruto de su trabajo en el Fondo de Cultura Económica, aparte sus funciones directivas en el periodo 1945-47, son sus traducciones de Whitaker, Schumpeter, Soule, Fellner y Chamberlain. Además, hizo la revisión de otras traducciones del FCE, entre ellas las de J.S. Mill y Harrod, p. 89.

${ }^{50}$ El primer director de la subsede de México de la CEPAL, inaugurada en junio de 1951, fue Eugenio Castillo. Victor Urquidi le sustituyó meses más tarde y propuso la contratación de Lara Beautell, como estrecho colaborador suyo.

${ }^{51}$ Hermano del ilustre pedagogo, se exilió en México al terminar la guerra civil.
} 
para el FCE, donde trabajó algunos años, y luego jugó un papel fundamental en los planes editoriales de la CEPAL. También trabajaron aquí Leopoldo Castedo, Francisco Izquierdo y Julián Calvo.

Por último, hemos de referirnos de nuevo a Prados Arrarte. Durante su estancia en la CEPAL, además de sus trabajos para este organismo, impartió algunos seminarios y cursos en la Universidad de Chile. Y cuando regresó a España a principios de 1954, de acuerdo con un plan previamente convenido con Prebisch, realizó un trabajo en el seno del Instituto de Cultura Hispánica sobre el comercio de España con Iberoamérica, que se publicó con el título de Estudio sobre la Unión Iberoamericana de Pagos. ${ }^{52}$

\section{CONCLUSIONES}

En este artículo, en el que se ofrece un anticipo de las principales conclusiones de un libro de próxima publicación en España, se estudia el trabajo de los exiliados republicanos españoles de 1939 que ejercieron como profesores de Economía en centros universitarios de América Latina.

Hubiera cabido esperar, por la inexistencia entonces de Facultades de Economía en España, que la nómina de los exiliados que se dedicaron a la enseñanza de la Economía en los países de acogida hubiese sido muy corta, o incluso inexistente. No fue así realmente, y ésta es la primera conclusión de este trabajo, debido fundamentalmente a dos razones: en primer lugar, porque en la mayor parte de estos países tampoco existían entonces centros universitarios de Economía, por lo que, conforme fueron creándose éstos en los años siguientes a la llegada de los exiliados españoles, a algunos de ellos les resultó más fácil encontrar empleo en la enseñanza de esta disciplina que en otras para las que había suficiente oferta de profesores por venir impartiéndose desde hacía tiempo; y en segundo lugar, porque en estos países se estaban iniciando entonces múltiples experiencias de desarrollo económico promovidas por el Estado, para las que fue necesario ir creando servicios de estadística económica y centros de investigación económica, que constituyeron una oportunidad para algunos profesionales tales como juristas, profesores mercantiles, empleados de banca o contables que habían estudiado alguna asignatura de Economía en España.

\footnotetext{
52 VELARDE, J. (1988): "El nacimiento de la CEPAL: Perspectiva española de hace cuarenta años”, Economistas, año 6, n⿳0 31, p. 45.
} 
En todo caso, también habría podido esperarse que el papel desempeñado por los exiliados españoles que se dedicaron a esta actividad hubiera sido más bien modesto. Tampoco fue así, y esta es nuestra segunda conclusión. Más de una docena de ellos llegaron a ser figuras muy relevantes en las universidades de distintos países latinoamericanos y jugaron un papel fundamental en la creación de los estudios de Economía y en la puesta en marcha de centros de investigación económica. Y en la nómina total de los economistas académicos exiliados que aparecen en este trabajo figura casi medio centenar de nombres, repartidos por casi todos los países de América Latina. Y como tercera conclusión, hay que señalar que, si sorprendentes pueden ser el número y la calidad de las aportaciones de los republicanos españoles en la enseñanza de la Economía en América Latina, más aun lo son los contenidos de sus trabajos, teniendo en cuenta que casi todos ellos se vieron obligados al exilio por su pertenencia a partidos políticos de izquierdas. Algunos de los que ejercieron como profesores e investigadores en el campo de la Economía militaron en el marxismo o en el dirigismo económico que caracterizaron la vida intelectual y política de los países de acogida en esos años, pero fueron los menos. La mayoría exhibió una excelente formación en la ortodoxia neoclásica y keynesiana e hicieron todo lo posible para que las políticas económicas de estos países se ajustaran a esta visión de la economía. Y los hubo incluso que mantuvieron una posición numantina en la defensa radical de la economía libre de mercado cuando todo estaba en su contra.

\section{REFERENCIAS}

ABELLÁN, J.L. (dir.) (1976): El exilio español de 1939, 6 vols., Madrid, Taurus.

ALBORNOZ DE LAESCOSURA, A. (1966): Trayectoria y ritmo del crédito agrícola mexicano, México, Instituto Mexicano de Investigaciones Económicas.

ALIENES UROSA, J. (1950): Características fundamentales de la economía cubana, La Habana, Banco Nacional de Cuba.

ALTED VIGIL, A. y LLUSIA, M. (2003): La cultura del exilio republicano de 1939, vols 2. Madrid, UNED.

AMO MORALES, J. y SHELBY Ch. (1950): La obra impresa de los intelectuales españoles en América, 1936-1945, Stanford, California.

BABB, S. (2001): Managing México. Economists from Nationalism to Neoliberalism, Princeton, Princeton University Press.

BALLVÉ, F. (1956): Diez Lecciones de Economía, México, D.F., Instituto de Investigaciones Sociales y Económicas.

Rev. hist. edu. latinoam. Vol. 15. Año 2010, pp. 197 - 224 
Manuel Martín Rodríguez

BORREGO DÍAZ, O. (2001): Che Guevara, el camino del fuego, Buenos Aires, Editorial Hombre Nuevo.

BOSCH GARCÍA, P. (1947): El control de las empresas del Estado en México, México.

CAPELLA, M.L. (1978): El exilio español y la UNAM, México, UNAM.

CARDOSO, F.H. et al. (1982): Medina Echavarría y la sociología latinoamericana, Madrid, Ediciones Cultura Hispánica.

CEPAL (1998): Cincuenta años de pensamiento en la CEPAL, 2 vols., Santiago de Chile, Fondo de Cultura Económica y CEPAL.

CORREA, E. y GIRÓN, A. (eds.) (2009): Economistas españoles del exilio en México, Madrid, Agencia Española de Cooperación Internacional para el Desarrollo.

COSÍO VILLEGAS, D. (1976): Memorias, México, D.F., Editorial Joaquín Mortiz.

DÍAZ ARCINIEGA, V. (1996): Historia de la Casa. Fondo de Cultura Económica (1934-1996), México, Fondo de Cultura Económica.

FAJNZYLBER, F. y MARTÍNEZ TARRAGO, T. (1976): Las empresas transnacionales. Expansión a nivel mundial y proyección de la industria mexicana, México D.F., Fondo de Cultura Económica.

FRANCO, G. (1957): Principios de Hacienda Pública, Buenos Aires, Ediciones de Ciencias Económicas S.R.L.

GAZOL SÁNCHEZ, A. (1973): El Tercer Mundo frente al Mercado Común Europeo, México, Fondo de Cultura Económica.

GAZOL SANTAFÉ, A. (1975): Latinoamérica: en el cambio, México, Fondo de Cultura Económica.

GIRAL, F. (1994): Ciencia española en el exilio (1939-1989). El exilio de los científicos españoles, Barcelona, Editorial Anthropos.

GONZÁLEZ DE LA VARA, A. y MATUTE, A. (coords.) (2002): El exilio español y el mundo de los libros, Guadalajara, México, Universidad de Guadalajara.

GUARDIADE SANZ, A. (1988): Historia de la Facultad de Ciencias Económicas y Sociales de la UCV, 1938-1958, Caracas, Faces UCV.

GUILLÉN, A. (1956): La conspiración de la oligarquía o la Radiografía del Plan Prebisch, Buenos Aires, Edit. Guitem (Imp. La Técnica impresora).

GUILLÉN, A. (1988): Economía libertaria, Bilbao, Fundación Anselmo Alonso.

GUILLÉN, A. (1990): Economía autogestionaria, Bilbao, Fundación Anselmo Alonso.

Rev. hist. edu. latinoam. Vol. 15. Año 2010, pp. 197 - 224 
HODARA, J. (1987): Prebisch y la CEPAL: sustancia, trayectoria y contexto institucional, México D.F., El Colegio de México.

IZQUIERDO, R. (1995): Política hacendaria del desarrollo estabilizador, 1958-1970, México, D.F., Fondo de Cultura Económica.

LABERGE, E.P. (1962): "Esapac. A Regional Experiment in Public Administration Training", Canadian Public Administration, vol. 5.3:305-311.

LAGUNILLA INARRITU, A. (1958): Desarrollo y equilibrio en la economía actual, Madrid, Aguilar.

LAGUNILlA IÑARRITU, A (1961): Dinero y capital, México, Universidad Autónoma de México.

LAGUNILLA IÑARRITU, A(1981): Historia de la banca y moneda en México, 2 vols., México, Editorial Jus.

LAMELAS, N. (1990): “Una concepción keynesiana acerca del desarrollo económico en Cuba: Julián Alienes", en Selección de materiales del pensamiento económico cubano, Universidad de La Habana.

LARA BEAUTELL, C. (1968): "La evaluación de proyectos de integración: algunos planteamientos", en Las inversiones internacionales públicas y privadas en el desarrollo y la integración de América latina, Washington, BID.

LATORRE RODRÍGUEZ, E. (1992): Sobre desarrollo y democracia, Santo Domingo, INTEC.

LEWIS, W.A. (1952): La planeación económica, México D.F., Fondo de Cultura Económica.

LIDA, C.E.; MATESANZ, J.A., Y VÁZQUEZ, J.Z. (2000): La Casa de España y El Colegio de México. Memoria 1938-2000, México, El Colegio de México.

LLORENS, V. (1975): Memorias de una emigración. Santo Domingo, 1939-1945, Barcelona, Ariel.

MANSILLA, A. (1965): Comentarios a la sección séptima del Tomo I de El Capital, La Habana, Publicaciones Económicas.

MARICHAL, C. (1989): A Century of Debt Crisis in Latín American: From Independence to the Great Depresion, 1820-1930, Princeton, Princeton University Press.

MARQUES SUREDA, S. y MARTÍN FRECHILLA, J.J. (2002): La labor educativa de los exiliados españoles en Venezuela, Caracas, Universidad Central de Venezuela.

MÁRQUEZ, J. (1945): Inversiones internacionales en América Latina, México, Banco de México.

MÁRQUEZ, J. (1969) Problemas del oro, México, CEMLA.

MÁRQUEZ DIEZ-CANEDO, J. (1966): "Los aranceles latinoamericanos y su efecto sobre la integración económica de la región”, en Revista Latinoamericana, año 6, 21. 
MARTÍN FRECHILLA, J.J. (2006): Forja y crisol. La Universidad Central, Venezuela y los exiliados de la guerra civil española, 1936-1958, Caracas, Universidad Central de Venezuela.

MARTÍN RODRÍGUEZ, M. y FERNÁNDEZ CLEMENTE, E. (2009): "Sesenta economistas académicos del exilio de 1936-1939”, en Fuentes Quintana (dir.) y Comín Comín (ed.): Economía y economistas en la Guerra Civil, Barcelona, Galaxia Gutenberg-Círculo de Lectores-Real Academia de Ciencias Morales y Políticas.

MARTÍNEZ TARRAGO, T. (2005): “Orígenes y creación del CIDE: testimonio de la maestra Trinidad Martínez Tarrago, en: Revista Análisis Económico, vol. XX, nº 43.

MATEO SOUZA, E. (1962): Los países de la ALALC, vistos desde México, México.

PALLARES RAMIREZ, M. (1952): La Escuela Nacional de Economía. Esbozo histórico: 1929-1952, México, UNAM.

PASCUAL, J. (1975): Un economista catalán: José Antonio Vandellós Sola (1899-1950), tesis doctoral, Universidad de Barcelona.

PÉREZ OLEA, M. (1955): "La Escuela Superior de Administración Pública de América Central (ESAPAC)”, en: Revista de Administración Pública, nº 17.

PIEDRAFITA SALGADO, F. (2003): Bibliografía del exilio republicano español (1936-1975), Madrid, Fundación Universitaria Española.

PRADOS ARRARTE, J. (1950): Problemas básicos de la doctrina económica, Buenos Aires.

PRADOS ARRARTE, J. (1955): Estudio sobre la Unión Iberoamericana de Pagos, Madrid, Imprenta Iberoamericana de Cooperación Económica.

PREBISCH, R. (1949): El desarrollo económico de América Latina y algunos de sus principales problemas (EC/CN. 12/89), Santiago de Chile, CEPAL.

RAMÍREZ GÓMEZ, R. (1972): La moneda, el crédito y la banca a través de la concepción marxista y de las teorías subjetivas, México D.F., UNAM, Instituto de Investigaciones Económicas.

SACRISTÁN COLÁS, A. (1973): Principios esenciales del crecimiento económico, México, Juan Pablos Editores.

SACRISTÁN COLÁS, A. (1985): Keynes ante la crisis mundial de los años ochenta, México, D.F., Siglo Veintiuno Editores.

SÁNCHEZ ALBORNOZ ABOIN, N. (1973): La población de América latina. Desde los tiempos precolombinos al año 2025, Madrid, Alianza Editorial.

SÁNCHEZ ANDRÉS, A. y FIGUEROA ZAMUDIO, S. (2002): De Madrid a México: el exilio español y su impacto sobre el pensamiento, la ciencia y el sistema educativo mexicano, Madrid, Comunidad de Madrid y Morelia, Universidad Michoacana.

Rev. hist. edu. latinoam. Vol. 15. Año 2010, pp. 197 - 224 
SANCHEZ-COVISA HERNANDO, J. (1974): Economía, mercado y bienestar. Estudios económicos. Selección y ordenación póstumas, Caracas, Talleres de Cromotip.

SÁNCHEZ SARTO, M. (2003): Escritos económicos (México, 1939-1969), Edición, introducción y notas de Eloy Fernández Clemente, Zaragoza: Prensas Universitarias de ZaragozaInstitución Fernando el Católico.

SCHWARZSTEIN, D. (1998): “Actores sociales y política inmigratoria en la Argentina. La llegada de los republicanos españoles”, Exils et migrations ibériques vers l'Amerique Latine, $\mathrm{n}^{\circ} 5$, París.

SERRA MORET, M. (1944): Diccionario económico de nuestro tiempo, Buenos Aires, Mundo Atlántico.

SERRA PUCHE, J. (1974): Las corporaciones internacionales y los grupos de poder: análisis teórico, México, UNAM.

SERRA PUCHE, J. (1975): El modelo neoclásico de crecimiento y los países con inversión insuficiente, México, El Colegio de México.

SERRANO MIGALLÓN, F. (2003): Los maestros del exilio español en la Facultad de Derecho, México D.F., Editorial Porrúa.

VELARDE, J. (1988): "El nacimiento de la CEPAL: Perspectiva española de hace cuarenta años", Economistas, año 6, no 31 .

VILA I COMAPOSADA, M.A. (1970): Geografia económica de Venezuela, Caracas, Monte Ávila Editores, C.A.

VILANOVA, F. (coord.) (1995): Carles Pi i Sunyer (1888-1971), Barcelona, Ediciones y Publicacions Ajuntament de Barcelona.

VILAR, J.B. (2006): La España del exilio. Las emigraciones políticas españolas en los siglos XIX y XX, Madrid, Editorial Síntesis.

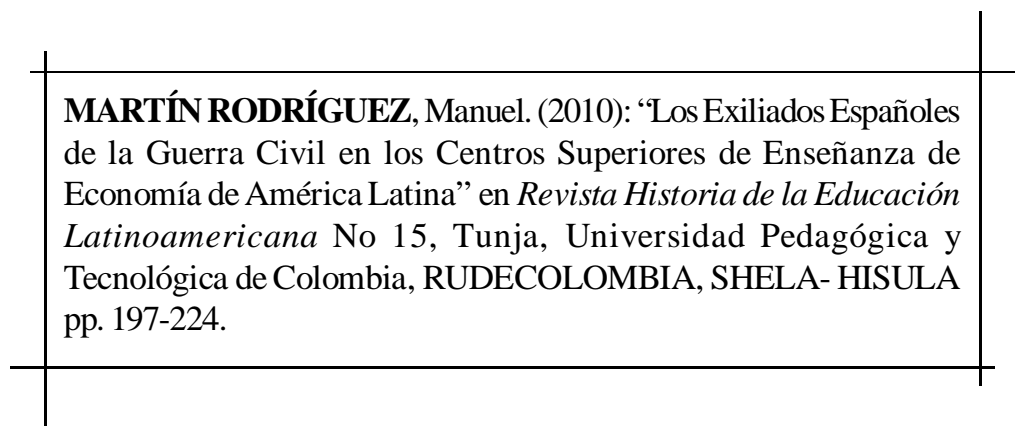

Rev. hist. edu. latinoam. Vol. 15. Año 2010, pp. 197 - 224 